\title{
The Prominence of In-Service Training on the Performance of Special School Teachers in South Africa in the Limpopo Province
}

\author{
Tshifhiwa Rebecca Mbuvha \\ University of Venda: South Africa
}

\begin{abstract}
One of the most pressing concerns surrounding the field of special education is to ensure there are highly qualified quality teachers for students with special needs. So far little attention has been paid to teacher's training programme which are necessary to upgrade their skills, knowledge and performance and to enable them to be more effective in teaching learners with special needs, particularly in South Africa. The purpose of this study was to investigate the effects of the in-service training (IST) programme for teacher's who work in special schools and evaluate its effects and appropriateness in South Africa basic education and training system in the Limpopo Province. The study sought to establish the contribution of IST to teacher's self-development and the effect of the use of South African Sign Language (SASL) and Braille as languages of instructions for teaching learners who are deaf and those with Blindness. The study adopted both quantitative and qualitative design. A sample of fifty (50) male and female teachers from special schools who attended the training in the Limpopo Province participated in this study. The findings show that the majority of teachers has gained knowledge on the use of SASL and Braille in teaching learners with special needs and this will enhance the quality of their teaching practices. Moreover, teachers evaluated the training programme as relevant and appropriate. One of the recommendations was to incorporate training of basic SASL and Braille in teachers training curriculum. Other recommendations include the sustainability of training for the next generation of teachers in special schools.
\end{abstract}

\section{Introduction}

One of the most important factors that influence a country's abilities to be economically competitive is the quality of its human resources, and therefore, of its education and training system, which is central to the development of its human resources. In every educational system, the availability of abundant, qualified and dedicated teachers constitutes a significant resource to which educational planners and administrators devote considerable efforts. The concern for teacher supply in the right quality and quantity is largely due to the wellaccepted maxim that teachers are the kingpins of the educational programme, for it is they who determine the direction of the system and ensure its success [1]. Hence, a competent and effective teacher is one of the key elements in the success of the teaching and learning process. Teaching, being creative and individualistic, required periodic rejuvenation of teachers attribute and upgrading of their technical know-how [5].

According to [8] the professional development of teachers is a lifelong, career-wide process that starts at training colleges and ends at retirement. Teachers have an ongoing commitment to maintain their professional expertise and they must recognise themselves as learners involved in the continual revision and enhancement of their knowledge and skills, and their teaching and learning approaches. [13] comments that teachers must engage in an appropriately balanced range of personal and professional development activities, enabling them to progress and learn in ways relevant to their individual needs and those of their students throughout their careers.

Teachers are facing ever increasing demands in trying to meet the needs of students in general education classroom. The diverse needs of students including those with disabilities, require teachers to keep abreast of the current research and literature, while struggling to find time to do so [1]. Teachers should be involved in professional development activities in order to remain current in the field and to enhance professional growth. The education of students with disabilities is made more effective by supporting high quality professional development for all staff who work with children with disabilities so that they have knowledge and skills to improve the academic achievement [2].

IST programs are specifically essential in preparing special education teachers. In a study examining the training needs for special education teachers, [18] indicate that the needs of teachers include teaching diverse students and using technology in instruction. It is for this reason that many countries run special education programs to develop comprehensive plans for training 
teachers who are working in the field of special education.

\section{Literature Review}

It is essential to continuously evaluate the process that leads to teacher preparation in order to prepare teachers who are able to conduct the duties dependent on them towards handling the challenges imposed by the present era [3], [12]. Teachers' training programmes are necessary in order to upgrade their skills, knowledge and performance, to enable them to be more effective.

[14] adds that IST is considered as a Continuous Professional Development (CPD) process. Because the world that teachers are preparing young people to enter is changing so rapidly, and because the teaching skills required are evolving likewise, no initial course of teacher education can be sufficient to prepare a teacher for a career of 30 or 40 years. Continuous Professional Development (CPD) is the process by which teachers (like other professionals) reflect upon their competences, maintain them up to date, and develop them further.

According to [7], a teacher-training programme is a process through which skills are developed, information is provided, and attitudes are nurtured, in order to help teachers to be more efficient in their work. Thus, training comes in as a solution to the lack of performance of the teachers or when there is need to effect change in the way things have been done [11]. Most fundamental, is the need for strong teachers' preparation programmes to provide training in the knowledge and skills necessary for working with students with special needs [9].

[15] argues that training programme can be perceived as a system development of certain necessary skill patterns in order to reach a certain level of competency in their execution of day-to-day tasks. Therefore, training is about identifying, assuring and helping planned learning in the key areas that enable teachers to perform current or future jobs [19]. It is aimed at both improving performance and capacity [4]. Thus, IST programmes have to equip teachers with valuable skills acquired through training that they deem necessary at their various schools [11].

In-service training has for many years been the driving force behind much changes that has occurred in the area of teaching and learning. As in any other profession, it is vital that teachers keep up to date on the most current concepts, thinking and research in their field. This, in turn supports in their 'lifelong learning' as educators, as professionals and as individuals who are responsible for the education of the next generation [5].

In-service training programs (ISTP) are necessary to re-orientate teachers to new goals and values, to train them in new teaching and learning methods, to prepare them to cope with curriculum change, and to provide them with the knowledge and skills to teach new learning areas [2]. ISTP programs also help teachers develop their own work thoroughly. They become more conscious of strategies for curriculum change and development, as many teachers enter the teaching profession without having received sufficient ISTP, though they may acquire basic skills in research and decision-making at various levels.

From the discussion above, it clearly shows that inservice training is important for teachers in school as a tool for professional development and to enhance their knowledge and quality of teaching and learning. Teachers are facing new challenges and changes in the education world and it's important for teachers to equip themselves with new knowledge and skills by attending in-service training in order for them to play an important and effective role as an educator. Besides that, the effectiveness of in-service training is important to ensure that the training is suitable and bring progressive effect to the teachers [5]. The effectiveness of the in-service training is influenced by the role of administrator, teacher's attitude, needs analysis and strategies used in the training program. According to [1] the effective ISTP should have at least two potential outcomes: (i) change of teachers' classroom practice, and (ii) change in teachers' belief and attitudes.

According to [12] the quality of teacher learning experiences is no less important than the quality of student learning experiences. Similar to their students, teachers appreciate opportunities to explore, reflect, collaborate with peers, work on authentic learning tasks, and engage in hands-on, active learning. Just as teachers strive to meet the needs of each individual student, professional development should aim to meet the needs of each individual teacher.

In conducting in-service training in schools, [12] said that time factor will affect the effectiveness of training. Too long of the training session will interfere the teachers concentration. While session held just after schooling time will not be suitable because teachers are tired after teaching. If it is conducted during weekend, some teachers would think that it is a holiday for them. Therefore, it is important to identify the most suitable time and session for training, teachers recommendation should be taken into account. This will make sure that teachers will be more ready and prepared to attend the training program.

In a study by [14] teachers need adequate time and support to participate in meaningful and varied professional development activities. The workload and tightly scheduled day of teachers often reduce their interest and willingness to participate in various activities. [14] mentions that at one school, a teacher had a teacher on assignment position which relieved her of classroom teaching responsibilities for a year. She viewed as most important a number of activities that other teachers complained about having little time for 
because of their full load of classroom responsibilities. These activities included leadership teams, district-wide committees, grant-writing teams, and school visitations. Grant-writing, for example, can rarely be accomplished in snippets of time each day. Given the time to focus on this activity, this teacher found it to be a highly rewarding learning experience that also held gains for the school. Furthermore, training programmes play a pivotal role, as it is through training that teacher's skills and attitudes can be changed for their own betterment. It is a process used to continue the teachers' education once they have received their certification in teaching and are employed in a professional position. Therefore, training programmes are of vital importance to teachers and to governments to pass on the latest innovations in teaching methods/strategies and new curricula [6].

Using a case study approach, [12] explores the possibilities and challenges of implementing strategies learnt through in-service training, in a public school in rural Pakistan. It was found that in-service courses have a positive impact upon the attitude and practices of the trainee teacher. However, due to various structural and cultural barriers, the teacher is not able to implement many of the strategies and ideas in the school context. The hierarchical structure of schools, teachers' workload, lack of resources and insufficient support from colleagues and management hinder the process of implementation. The study suggests that in-service training should provide the trainees with ideas and skills to cope with the structural and cultural challenges at school. Moreover, ongoing support and encouragement from colleagues, course facilitators and management is required to sustain the implementation of strategies learnt during training.

Ongoing opportunities to work with and learn from others. The premise behind this condition is that learning may be enhanced through exposure to a variety of other individuals who provide a greater range of referents for assessing one's own ideas, performance, and need for learning [14] Applied to professional development, this condition supports the view of teachers as lifelong learners and counters the problem of teacher isolation.

Limpopo is one of the nine provinces of South Africa, and formed from part of the old Lebowa Kgomo, Venda and Gazankulu before South Africa's first all-race elections on 27 April 1994. It was named Northern Province in December 1994 and then renamed 'Limpopo Province'. The province is one of the poorest province in South Africa, with 5404868 population [17].

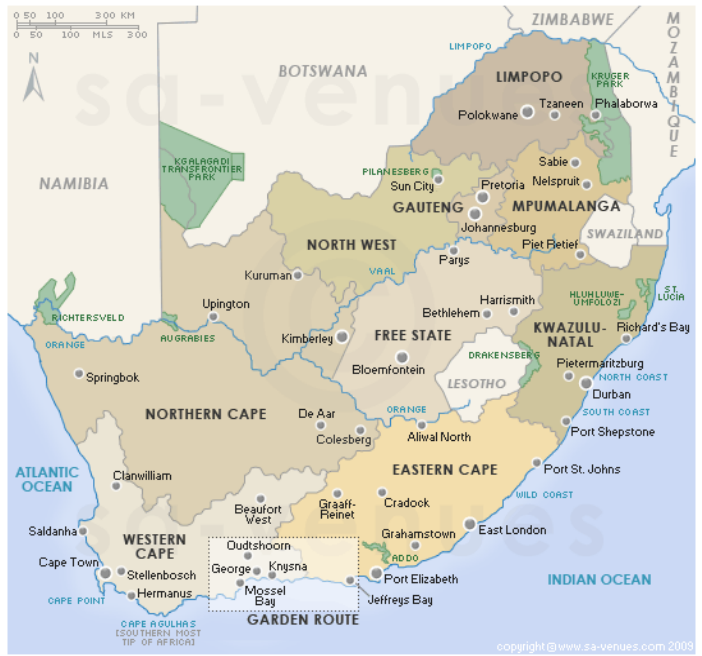

Figure 1. A map of South Africa showing the location of the nine provinces. (SA-VENUES. com. online,

Retrieved 11 June 2016)

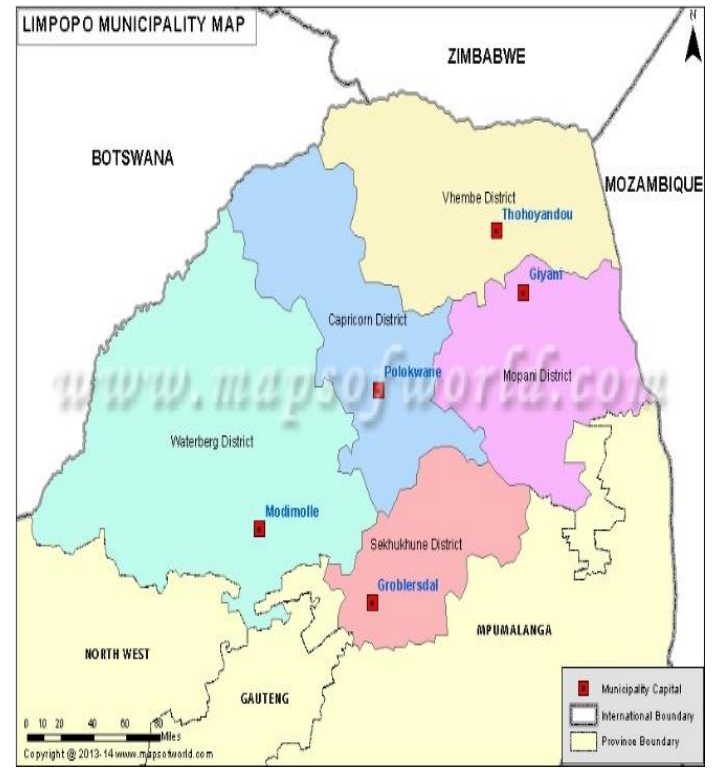

Figure 2. Five districts of Limpopo Province in which the study was conducted

The province is divided into five district municipalities, namely Capricorn, Mopani, Greater Sekhukhune, Vhembe and Waterberg [17]. The province has 7 school for the deaf and 6 schools for the blind distributed across the province. Teachers from this special schools were undergoing Braille and SASL since 2014. Teachers' competency in both Braille and SASL is very important for the teaching of learners with visual and hearing disabilities. 


\section{Purpose of the study}

Special education teachers are required to be generally competent in many areas especially in competencies in interpersonal skills, including counselling and presenting teaching services for students with special needs. Generally speaking, the issue of improving strategies used for teaching children with special needs has not received the attention it deserves. Indeed, the field of special education in Jordan is still short of well-trained educational staff that possesses the necessary teaching skills and competencies. The majority of teachers working with children with special needs in Jordan have indeed never received the appropriate training in special education during their preservice training programs. Hence, the problem of this study comes from this serious need for an in-service training program specifically designed for Limpopo Province special education teachers.

Teachers are seen as key players in implementing inclusive education. However, extremely little attention has been paid to teachers' preparation, particularly in the Limpopo Province in South Africa. The aim of this study was to evaluate the effect of Braille and SASL IST on the teachers from special schools in the Limpopo Province in South Africa. The main objective of this training programme was to enhance the teachers' performance and help them acquire new knowledge and skills.

\section{Methodology}

\subsection{Research Design}

The study used both quantitative and qualitative research methods. The aim of this study was to evaluate the effect of Braille and SASL IST on the teachers from special schools in the Limpopo Province in South Africa as seen from their perspective. The type of research question, therefore, also required that this study follow an interpretive paradigm within qualitative research methodology framework, since the reality to be studied consisted of participants' subjective experiences of the external world [18].

According to [18] paradigms act as perspective that provide rationale for the research, and commit the researcher to particular methods of data collection, observation and interpretation. Furthermore, paradigms constitute the epistemological, the ontological and methodological premises of the researcher. Therefore since my goal was to understand how teachers constructed their own meaning of the experience on the training.

\subsection{Population}

The participants were teachers from special schools in the Limpopo Provence who received Braille and SASL training in an attempt to limit extraneous variables as far as possible by keeping the group similar in terms of teaching experience and also on the basis of the assumption that their experience might be the same as they work on the same province.

\subsection{Sample}

We sampled teachers from various special schools in the province who attended Braille and SASL training to participate in this research by using purposive and convenience sampling. We selected convenience sampling method because the participants who are willing and available to take part in the study participated. During one of the training session teachers were notified of the project and its purpose and then asked to register their willingness to participate. Fifty (50) teachers, male and female participated in this study.

\subsection{Instruments}

Satisfaction questionnaire was distributed to teachers who were attending Braille and SASL training in 2016.

\subsection{Data Analysis}

Data analysis is the systematic search for meaning and a means to process data. In other words, the process involves making sense of data [17]. Data analysis involves the process of transforming data to answer the initial research question. A qualitative researcher's effort is focussed on interpreting and understanding the social world of the participants. Data collected was used to establish the effects of the IST programme for teacher's who work in special schools in South Africa in the Limpopo Province and how this training support contributes towards their performance.

\section{Satisfaction Survey Results}

\subsection{Biographical information}

The sample comprises of 50 teachers, of whom $(42.2 \%)$ are males and $(57.7 \%)$ are females. This indicates that female teachers outnumber the male teachers. In terms of experience, (24.4\%) of the participants (males and females) had less than three years of teaching experience, while $(75.5 \%)$ of them (males and females) had more than three years of teaching experience. In terms of educational level, (60\%) 
participants possessed either certificate or diploma in Inclusive Education or Special Need Education.

Approximately, fifty (50) teachers participated in this study and out of 50 questionnaires that were distributed, 5 were spoiled. The training participants were surveyed at the end of the training programme to evaluate their views on the effectives and impact of the training in their work as well as their prior experiences. In total 45 training participants responded to the survey. We test if the responses are statistically different from random responses using a normal approximation to the Binomial Distribution for binary responses and a Multinomial Distribution for multiple responses. From this we obtain p-values which in this case can be seen as the probabilities that the responses are random. Therefore, a low p-value would imply that responses are not random and that reasonable conclusions can be drawn from them.

5.1.1. Prior Learning. A significant proportion of participants $67 \%$ had some skill in the subject matter before the training. We obtain $\mathrm{z}$-score of 2.23 with a $\mathrm{p}$ value 0.01 meaning the result was also statistically significant.

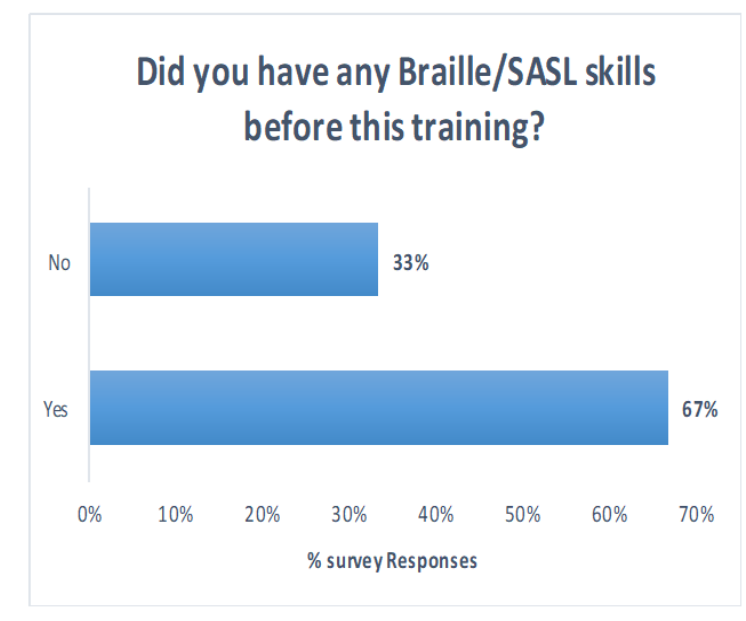

Figure 3. Showing the respective proportions of participants who had prior skills in Braille and

SASL

We thus conclude that within the population teachers there is in general some of knowledge of Braille and SASL. This prior knowledge also positively affected the learning experience of trainees with those who are more knowledgeable assisting their less knowledgeable colleagues in classes.

5.1.2. Effectiveness in Improving Personal and Professional Competencies. The survey respondents significantly at $96 \%$ presented the view that their respective training in Braille and SASL will make an improvement in their personal and professional competencies.

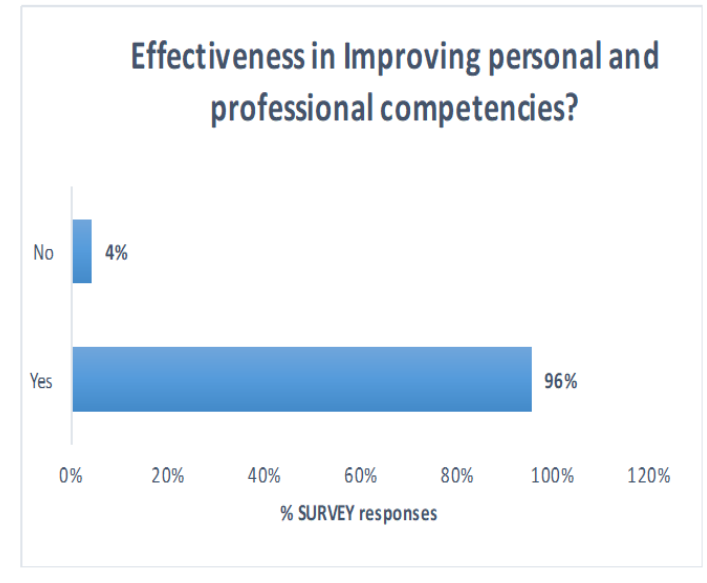

Figure 4 Participants responses on the effectiveness of the training on their competencies

This result was highly statistically significant with a p-value of $1 e-14$. In the context of some participants having some prior knowledge this showed that participants felt that the training further enhanced their knowledge in the subject areas.

5.1.3. Overall Helpfulness and Recommendation. $82 \%$ of training participants found the training to be extremely helpful with the remaining $18 \%$ finding it somewhat helpful.

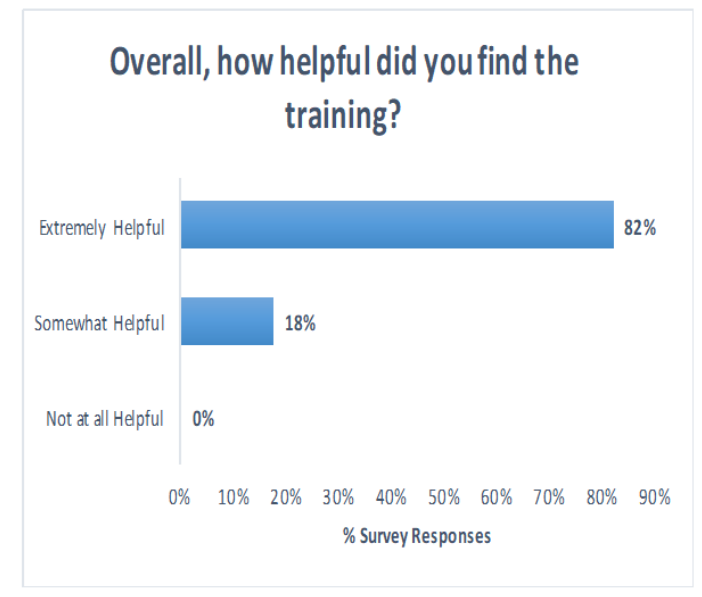

Figure 5. Participants responses on the overall helpfulness of the training 




Figure 6. Participants responses on whether they would recommend the training to their other teachers

What is also notable is that none of the participants responded that it is not helpful at all. This result is highly statistically significant with a p-value of 1e-19. Participants were also asked if they would recommend the training to their fellow colleagues with $98 \%$ percent of them responding that they will definitely recommend the training. This result is also highly statistically significant with a p-value of $1 \mathrm{e}-10$. This is a key element for the sustainability of the programme.

\section{Discussion}

The study found that IST will not only develop teachers 'skills, but the learners with special needs will also benefit. Some participants commented that the training has improve their teaching practice and suggested that the training should be sustained for the next generation of teachers in special schools. Lack incentives after completion was raised as a concerns. They added that the incentives will serve as a motivation for the teachers who registered for the programme. It was revealed that prior the training some teachers were using learners to mark scripts as they were unable to mark Braille.

The study also revealed that teachers were unable to use SASL as a language for instruction for learners with hearing disabilities. The problem of teachers not able to use SASL when teaching has a negative impact on the hearing impaired learners to complete Grade 12. Teachers commented that Braille and SASL training is a life changing programme. One participant said: "I was deployed to the Special School without any knowledge of SASL and now I able to use South African Sign Language as the language of teaching". It was suggested that this kind of training should be followed by advanced Braille and SASL training. One Braille teacher commented: "As I am teaching higher grades I am looking forward for advance Braille which also includes contractions". The participants commented that IST was long overdue, especially for those who were deployed to the special school without Braille or SASL skills. A SASL teacher said: "It was taking a long time for me to learn SASL, as I was teaching myself. Now is so motivating to learn with others educators and also learning from each other". The study recommended that parents should also be trained so that they are able to communicate with their children during school holidays. "It is important for the parents to be trained on how to use SASL because after holidays learners forget some of the words after school holidays". Participants also recommended that IST for Braille and SASL should also include teachers in fullservice schools. One teacher said: "I feel like I have entered another world, where I can teach with confidence".

Other suggestions includes the incorporation of Basics of SASL in teachers training programmes at universities and colleges. Overall, it is demonstrated that IST is important to enhance teacher's learning experiences and update their knowledge. As a result, training indeed had contributed on the teachers' practice as perceived by the participants themselves.

\section{Conclusion}

The discussions of the qualitative and the quantitative results revealed the importance of in-service training programmes, especially who adopt the workshop method aiming at enhancing the performance of the teachers and improving their educational proficiency in order to help them acquire the skills and the knowledge plus keeping them informed about the latest developments in the educational field. Furthermore, the IST play an important role in upgrading skills, knowledge, and performance of teachers to be more effective.

From this study it can be concluded that IST programmes are important methodologies that can be used to develop and improve teachers' skills in order to enhance their instructional competencies and provide them with the latest about educational developments. Most educators (those deployed to special schools) said they received the support they needed to teach students with disabilities to a moderate or great extent. This support included help from special education teachers, special procedures for working with students, continuing professional development on the needs of students with disabilities, and assistance from paraprofessionals.

The findings of this study revealed that, IST has several positive effects on the performance of teachers for the deaf and blind learners. These include: selfdevelopment of the teachers, gaining of new skills that enables them perform their tasks better and adequate and timely completion of syllabuses. All these effects have a direct input towards better performance of teachers. 
Therefore IST is a very important undertaking in improving the performance of teachers.

It was also found that there are significant effects of the training program module based on instructional competencies in improving the knowledge, performance, professional, and personal competencies of the experimental group teachers. These effects can be attributed to content of the training program module. It included instructional experiments, activities, and instructional skills, which helped provide the teachers with the appropriate instructional competencies to develop their knowledge and performance.

Despite the positive findings, there are some limitations in this study. The first would be the sample size of only 50 participants. Thus, the results of the participant responses might be limited. Another would be the demographic concern. A majority of the participants already has experienced in teaching students with special needs or in inclusive settings.

\section{Recommendations}

The following recommendations are made on the basis of these reflections:

- The training should be sustained for the next generation of teachers in special schools.

- There should be some form of incentives to serve as motivation for the teachers

\section{References}

[1] Al-Zoubi, S. and Bani Abdel Rahman, M. (2011). The Effects of a Training Programme in Improving Instructional Competencies for Special Education Teachers in Jordan. International Research Journals, 2(3), 1021-1030.

[2] Al-Zoubi, S., Bani Abdel Rahman, M. and Ismail, H. (2010). The Effect of in-Service Training Program in Improving Performance Competencies for Learning Disabilities Resource Room Teachers in Jordan.Educators Digest. 10: 4-11.

[3] Bouck, E. (2005). Secondary special teachers: Perspectives of preservice preparation and satisfaction. Teacher Education and Special Education, 28, 125-139. [4] Bursey, K. (1997). Development of an in-service programme on phonemic awareness for teachers and early childhood teachers. Unpublished master thesis. Memorial University of Newfoundland.

[5] Che, O. and Che, M. Z. (2014). The need for inservice training for teachers and its effectiveness in school. International Journal of Innovation Education and Research, 2-11, 1-9.

[6] David, C. (2001). Characteristic and competencies of teachers of gifted learners. Roeper Rev. 23: 1-8.

[7] Davis, S, and Davis, B. (1998). Effective training strategies. San Francisco: Barett-Koehler Publishers.

[8] European Training Foundation, (2013). School-based in-service teacher training in Montenegro, Luxembourg: Publications Office of the European Union

[9] Heng, M. \& Tam, K. (2006). Special education in general teacher education programmes in Singapore. Teacher Education and Special Education, 29, 149-156.

[10] Jenkins, A. A. and Yoshimura, J. (2010). NoT another In-service! Meeting the Special Education Professional Development Needs of Elementary General Educators Teaching Exceptional Children, vol.42, no 5

[11] Kennedy, M. (1991). Some surprising findings on how teacher learn to teach. Educational Leadership, 49, p 17.

[12] Koch, S. (2007). Training rural special teachers online to teach social skills. Aural Special Education Quarterly, 26, 16-20.

[13] Khuzai, A. (2001). Mastery level of effective teaching skills among resource teachers. Unpublished Master's thesis. The University of Jordan.

[14] Nawab, A. (2017). What Difference Could InService Training Make? Insights from a Public School of Pakistan. Teacher Development, 21, 142-159.

[15] Obiakor, F. and Utley, C. (1996). Rethinking preservice and IST programmes for teachers in the learning disabilities. (ERIC Document Reproduction Services No.: ED 379594).

[16] Sandholtz, J.H. (2002). In-service training or professional development: contrasting opportunities in a school/university partnership. Teaching and Teacher Education, 18 (2002) 815-830

[17] Statistics South Africa. (2014). Pretoria: Statistics South Africa.

[18] Westat, I. and Rockville, M. (2002). Local administrators' role in promoting teacher quality. SPeNSE summary sheet. (ERIC Document Reproduction Services No.: ED469460). 
International Journal of Technology and Inclusive Education (IJTIE), Volume 7, Issue 1, June 2018

[19] Wigle, S and Wilcox, D. (2002). Special education directors and their competencies on CEC identified skills. Educ. 123: 276-280. 